\title{
Handling environmental values in product assessments: voices from practice
}

\author{
Magnus Bengtsson*
}

Hydrology and Water Resources Engineering

Institute of Industrial Science, The University of Tokyo

4-6-1 Komaba, Meguro-ku, Tokyo 153-8505, Japan

Fax: +81-3-5452-6383 E-mail: bmbengtsson@gmail.com

*Corresponding author

\section{Anne-Marie Tillman}

Environmental Systems Analysis

Chalmers University of Technology

SE-412 96 Göteborg, Sweden

E-mail: anne-marie.tillman@esa.chalmers.se

\begin{abstract}
Many life cycle assessments include weighting of environmental impacts. The way these trade-offs are handled affects to what extent an assessment leads to relevant and convincing results. To explore reactions to weighting, group interviews with representatives of Swedish authorities, industrial and public purchasing departments, an environmental nongovernmental organisation, and research bodies were carried out. We conclude that support for study outcomes can best be reached through improved capacity to handle and communicate value differences. The findings suggest that weighting approaches that can accommodate different perspectives, such as panels, may be more effective. The study also revealed that the need to handle value choices in assessments is often poorly understood. This might impede effective assessments since there is a risk of value vacuums, situations where no one takes responsibility for setting environmental priorities.
\end{abstract}

Keywords: Life Cycle Assessment (LCA); weighting methods; environmental trade-offs; priority setting; efficiency; legitimacy; responsibility.

Reference to this paper should be made as follows: Bengtsson, M. and Tillman, A-M. (2005) 'Handling environmental values in product assessments: voices from practice', Progress in Industrial Ecology - An International Journal, Vol. 2, No. 2, pp.200-222.

Biographical notes: Magnus Bengtsson is presently a JST post doctoral researcher at The University of Tokyo, Japan. He has a MSc in Industrial Engineering and Management from Chalmers University of Technology, Göteborg, Sweden, and a BA in History from Göteborg University. In 2002, he finished his $\mathrm{PhD}$ in Environmental Systems Technology at Chalmers University of Technology. Among his research interests are environmental assessments, environmental valuation and sustainability concerns in decision making processes. When trying to contribute to these fields he seeks to combine quantitative and qualitative research approaches. Much of his research has been related to life cycle assessment and urban water systems. 


\begin{abstract}
Anne-Marie Tillman is Professor in Environmental Systems Analysis at Chalmers University of Technology, Göteborg, Sweden. A Chemical Engineer by training, she received her $\mathrm{PhD}$ in Engineering Chemistry in 1987. Since 1990, her research has focused on environmental systems analysis, starting from Life Cycle Assessment (LCA) (an effort now matured into a LCAtextbook). In later years the scope of her research has broadened to cover an array of environmental systems tools, including environmental assessment of technical change, sustainability indicators and environmental information systems. Anne-Marie Tillman holds various leadership positions at Chalmers. She leads the research group Environmental Systems Analysis and is the pro-prefect of the Department for Energy and Environment. She is also a member of the Royal Swedish Academy of Engineering Sciences. She actively interacts with society outside academia. Activities range from education to joint industry-academia projects to more long-standing collaboration in the supervision of industrially employed doctoral students.
\end{abstract}

\title{
1 Introduction
}

Most environmental product assessments involve trade-offs among environmental impacts. To draw conclusions from such studies, certain impacts need to be prioritised through some form of valuation of their relative severity. Consequently, in a survey of Life Cycle Assessment (LCA) studies carried out in Nordic countries, Hanssen (1999) found that impact assessment methods with a weighting component had been used in $80 \%$ of the cases. The way in which this value-laden priority setting among impacts is handled affects the relevance and effectiveness of a study. Therefore, it is a significant research task to investigate how the weighting component might affect interested parties' acceptance of assessment outcomes.

Studies of weighting in LCA have mostly dealt with internal qualities of formal weighting methods, qualities such as consistency, scope, and scientific rigour (for example, Baumann and Rydberg, 1994; Bengtsson, 1998; Braunschweig et al., 1996; Finnveden, 1997; 1999; Finnveden et al., 2002; Hertwich et al., 1997; Lindeijer, 1996; Powell et al., 1997). Although such qualities are important, it is not clear how and to what extent they contribute to effective outcomes in terms of acceptance and support from interested parties.

Acceptance of assessment outcomes is influenced by a number of factors. Clark and Dickson (1999) investigated what makes assessments of global environmental change effective. They identified three main characteristics: saliency, credibility, and legitimacy. These characteristics were specified in EEA (2001) in the following way:

- Saliency, or relevance, is intended to reflect the ability of an assessment to address the particular concerns of a user.

- Credibility is intended to reflect the scientific and technical believability of the assessment to a defined user.

- Legitimacy is a measure of the political acceptability or perceived fairness of an assessment to a user.

Even though Clark and Dickson's assessments are larger in scale than the normal product assessment, it seems plausible that an LCA project also needs to be salient to its intended 
users, credible with regard to the scientific methods and data employed, and legitimate in the way the assessment is carried out. However, as mentioned above, research on weighting in LCA has primarily been concerned with the scientific credibility aspect. We believe that a broadened research agenda that also addresses the saliency and legitimacy dimensions would benefit both the practitioners of environmental product assessments and those involved in the development of new methods and tools for such assessments.

A recent review article on 'impact assessment practice' (Pennington et al., 2004) gave only very limited attention to trade-offs and weighting, and did not include any empirical information on how weighting approaches are used in practice. We believe that analytical research of assessment methods needs to be complemented by empirical investigations where environmental assessments are regarded as social practices. Among the few researchers who have addressed the issue of how LCA works in real-life settings and how various actors think and argue about the judgement of environmental impacts are Bras-Klapwijk (1999), Tukker (1999), and van Eeten (1999). However, weighting and priority-setting was not the main subject of their studies.

One objective of this article is to investigate how relevant and convincing outcomes of environmental product assessments can be achieved when environmental trade-offs are involved. We focus especially on assessments where a life-cycle perspective is used. By taking an empirical approach to environmental assessments, and the handling of trade-offs in such assessments, we seek to investigate what are acceptable methods and principles from the perspectives of potential receivers of LCA studies. A similar interpretive approach to weighting methods was used by Bengtsson (2001), but with a focus on product developers and product managers in industry.

However, the legitimacy of environmental product assessments is not only a matter of acceptance of methods or abstract principles, but also a matter of procedural aspects such as who is involved and who makes the values choices. Research on user requirements for Environmental Product Declarations $(E P D)^{1}$ by Solér (2001) pointed out several questions to be addressed by future research, one of which was the following: "Who...is responsible for making value choices and weighting in relation to EPDs?" Inspired by Solér's question, which, according to our experience, is relevant not only to EPDs, but also to the effectiveness and legitimacy of environmental product assessments in general, a second objective of the present study is to investigate various views regarding who ought to make value choices in environmental product assessments.

\section{Method}

Group interviews and focus groups are widely used today for studying people's perspectives, experiences, opinions, and concerns (Barbour and Kitzinger, 1999; Bloor et al., 2001). We conducted the study by means of three semi-structured group interviews of about two hours each. The three groups included 15 representatives of actors relevant to product-related environmental information. The first group included purchasers, both from the private and public sectors; the second was mixed, including environmental researchers, people working for local authorities, and one NGO representative; the third included people working for various national authorities. The composition of the three interview groups is shown in detail in Table 1. 
Table 1 Participants in the interview groups. $\mathrm{M}$ and $\mathrm{F}$ indicate male and female participants, respectively.

\begin{tabular}{|c|c|c|}
\hline $\begin{array}{l}\text { Group 1 [IG 1] } \\
\text { Purchasers }\end{array}$ & $\begin{array}{l}\text { Group } 2[I G 2] \text { Researchers, } \\
\text { local authorities, and an NGO }\end{array}$ & $\begin{array}{l}\text { Group } 3 \text { [IG 3] Managers and } \\
\text { project leaders from the } \\
\text { following national authorities }\end{array}$ \\
\hline $\begin{array}{l}\text { Logistics manager, chemical } \\
\text { producer }(\mathrm{M})\end{array}$ & $\begin{array}{l}\text { Researcher/lecturer in } \\
\text { sustainable architecture (M) }\end{array}$ & $\begin{array}{l}\text { Industry unit, sustainable } \\
\text { development department, }\end{array}$ \\
\hline $\begin{array}{l}\text { Environmental coordinator, } \\
\text { major daily products chain (M) }\end{array}$ & \multirow{2}{*}{$\begin{array}{l}\text { Researcher/lecturer in } \\
\text { chemical environmental } \\
\text { science }(\mathrm{M})\end{array}$} & $\begin{array}{l}\text { EPA }(\mathrm{F}) \\
\text { Energy administration }(\mathrm{M})\end{array}$ \\
\hline \multirow{2}{*}{$\begin{array}{l}\text { Project leader, architect } \\
\text { bureau with environmental } \\
\text { focus }(F)\end{array}$} & & Evaluation unit, EPA (M) \\
\hline & $\begin{array}{l}\text { Project leader, regional } \\
\text { business development unit (M) }\end{array}$ & $\begin{array}{l}\text { Agency for innovation } \\
\text { systems }(M)\end{array}$ \\
\hline \multirow[t]{2}{*}{$\begin{array}{l}\text { Procurement officer, major } \\
\text { municipality (F) }\end{array}$} & $\begin{array}{l}\text { Head of technical office, major } \\
\text { municipality }(M)\end{array}$ & $\begin{array}{l}\text { Business development } \\
\text { agency }(\mathrm{F})\end{array}$ \\
\hline & $\begin{array}{l}\text { Head of environmental } \\
\text { exhibition centre }(\mathrm{M})\end{array}$ & Chemicals inspectorate (M) \\
\hline
\end{tabular}

All participants had relatively long experience dealing with environmental assessments at various levels and in various roles. Some had acted as commissioners of LCA studies, at least one participant had been in the reference group of an LCA study, but none had carried out a full study of their own. They were all familiar with the life-cycle perspective. Some participants were selected because we already knew that they had experience relevant to our study, while others were recommended to us for the same reason. Some participants already knew each other, especially in groups two and three, but did not work together on a regular basis. All group discussions were conducted during the autumn of 2001, and the authors of this article both participated in the group meetings as facilitators.

The interview sessions were divided into two parts: the first deals with the comparison of products from an environmental perspective in general, and the second focuses on LCA-specific questions. In the first part, we asked the participants to give examples of what they thought were environmentally adapted products, and to discuss various concepts such as 'environmentally friendly', 'recyclable', and 'sustainable'. We also asked the participants to discuss situations where environmental trade-offs occur, and how, based on their own experiences, such situations should be handled.

In the second part of the interviews, we presented an LCA case study that employed two weighting methods. We asked the participants to discuss the results of that study and the relevance of the weighting methods to the interpretation. We also showed the participants general principles that have been used for weighting in LCA, and asked them to discuss strengths and weaknesses of those principles.

The group discussions were recorded and transcribed verbatim to enable a detailed analysis. Since the interviews were semi-structured, some questions were relatively well-developed and the answers to these could be easily analysed. Apart from answering our direct questions, the participants also brought up many other matters or themes that reflected their concerns and their ways of understanding environmental assessments. They also commented extensively on each other's answers and added opinions and stories that either supported or countered other participants' comments. In introducing the discussions, we explicitly asked for this kind of interaction and pointed out that we did 
not expect the group to reach a consensus. Several readings of the transcripts allowed us to identify recurring themes that were relevant to the objectives of the study, a procedure often referred to as indexing in the methodology literature (see, for example, Bloor et al., 2001). For each of the identified themes, illustrative quotations or related lines of reasoning were collected.

Our study is qualitative and includes only a small number of participants, so statistical significance is not the aim. Rather, the purpose is to investigate whether qualitatively different logical approaches, i.e., ways of thinking and reasoning about value choices and weighting in environmental assessments, can be discerned. Knowledge of such patterns is important for both LCA practitioners and researchers. Even though all participants in the study are Swedish, we believe that much, if not most, of our findings, and the discussions we base on these findings, are relevant also to other cultural contexts.

\section{Results and analysis}

This section presents the main findings of our study and relates them to previous research. Each quotation is labelled by interview group, for example [IG 1] indicates quotations from the first interview (see Table 1 for a description of the groups). The quotes were edited during translation for improved readability. The first part of the section focuses on LCA, while the second part deals with environmental product assessments and environmental values more in general.

\subsection{Life cycle assessment}

One part of the interviews focused on methods for weighting and impact assessment in LCA. To illustrate how weighting methods have been used in an actual case, we presented a study to the participants that compared PVC and linoleum flooring (Jönsson, 1995). In addition, we discussed general principles for weighting. In the flooring case, we asked the participants to pretend that agreement had been reached on how the technical system should be modelled and what data should be used in the inventory. This was done because we wanted the groups to concentrate primarily on the impact assessment and interpretation.

\subsubsection{Weighting in general}

In our presentation of the LCA study, we included results from the weighting methods employed in the original study: EPS (Steen and Ryding, 1992), which is based on economic measures of environmental impact; and Swedish Ecoscarcity (Baumann et al., 1993), which is based on political targets for reduction of emissions and resource use. ${ }^{2}$ After describing how the technical systems had been modelled, we showed both a fully aggregated comparison of the two flooring materials and pie-charts which showed the relative contribution of various environmental impacts to the total environmental load. The two methods ranked the materials differently and emphasised different impacts. Figures 1 and 2 show examples of how the results were presented to the participants. 
Figure 1 Weighting example shown to the participants. The environmental load of PVC and linoleum flooring evaluated with two weighting methods: EPS (a) and ecoscarcity (b). The methods rank the materials differently.
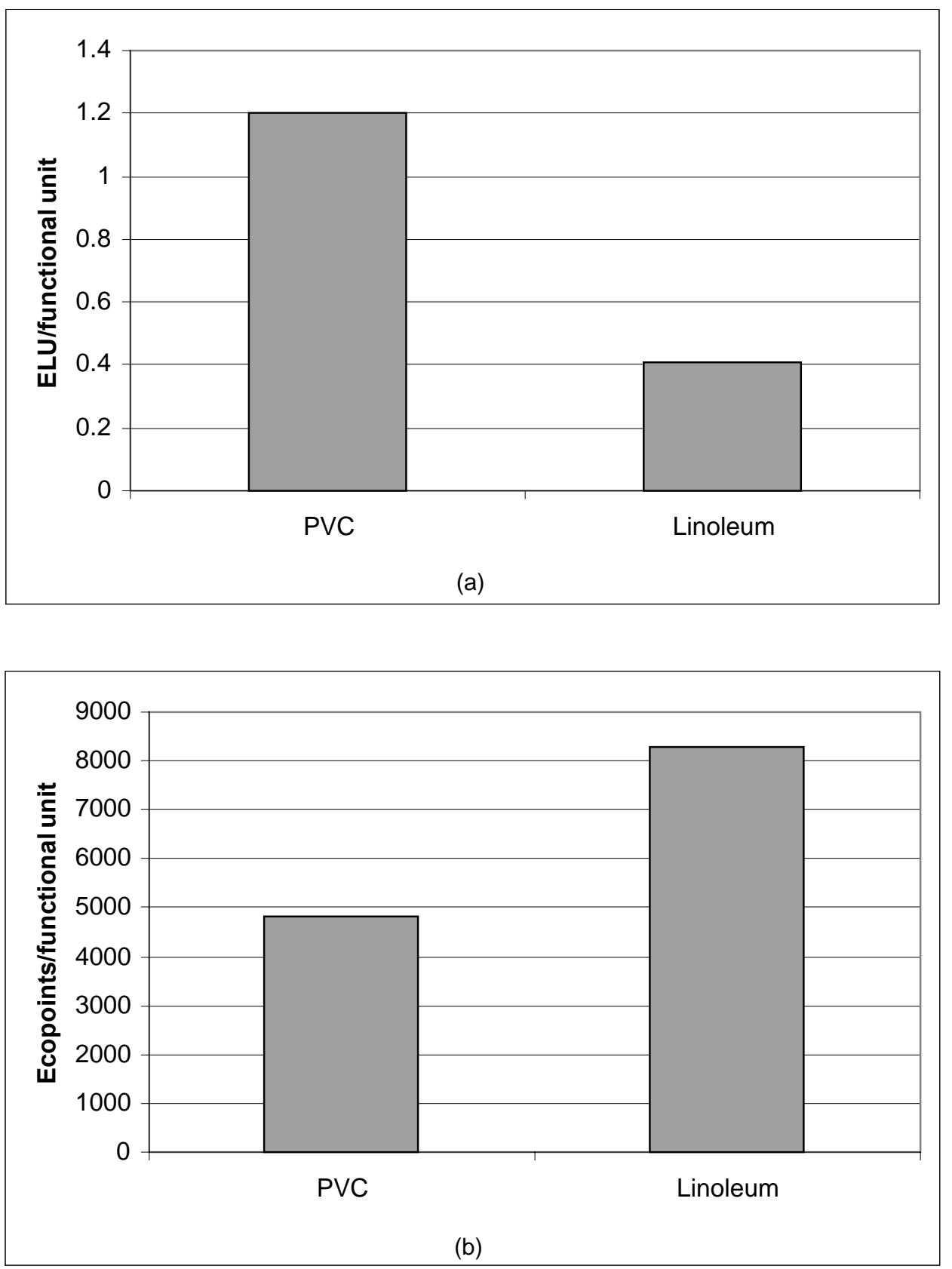
Figure 2 Weighting example shown to the participants. The relative contribution of various environmental impacts to the total environmental load of PVC and linoleum flooring, evaluated with two weighting methods: EPS (a-b), Ecoscarcity (c-f). The methods lay emphasis on different impacts.

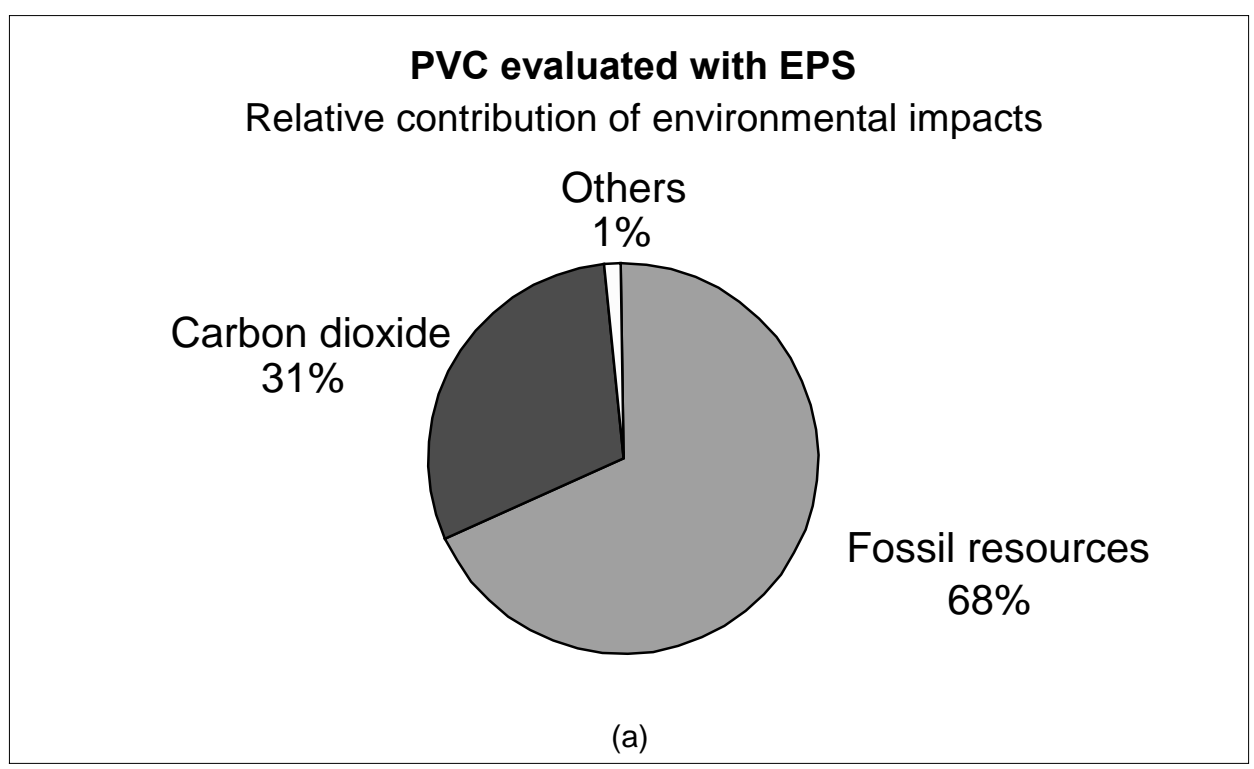

\section{Linoleum evaluated with EPS}

Relative contribution of environmental impacts

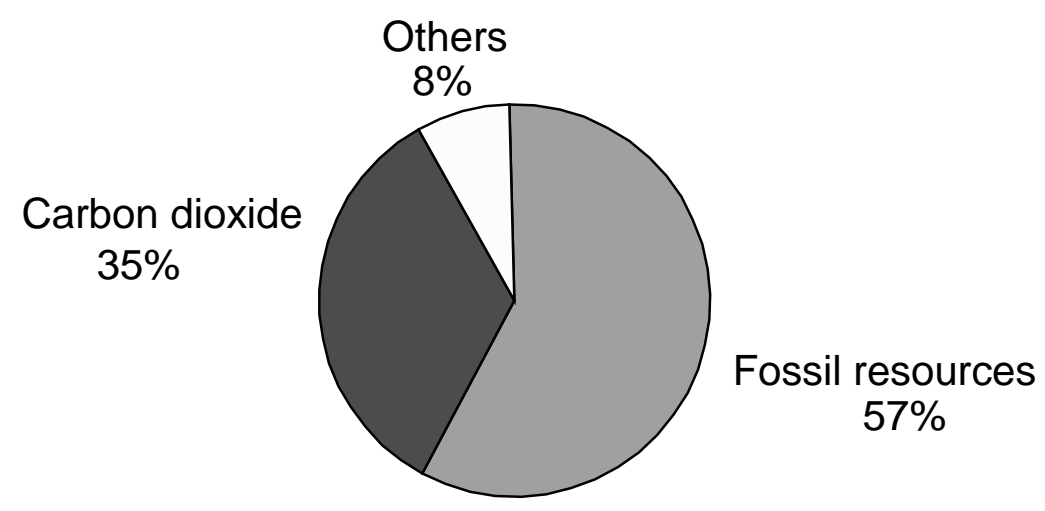

(b) 
Figure 2 Weighting example shown to the participants. The relative contribution of various environmental impacts to the total environmental load of PVC and linoleum flooring, evaluated with two weighting methods: EPS (a-b), Ecoscarcity (c-f). The methods lay emphasis on different impacts. (continued)

PVC evaluated with ecoscarcity

Relative contribution of environmental impacts

Others

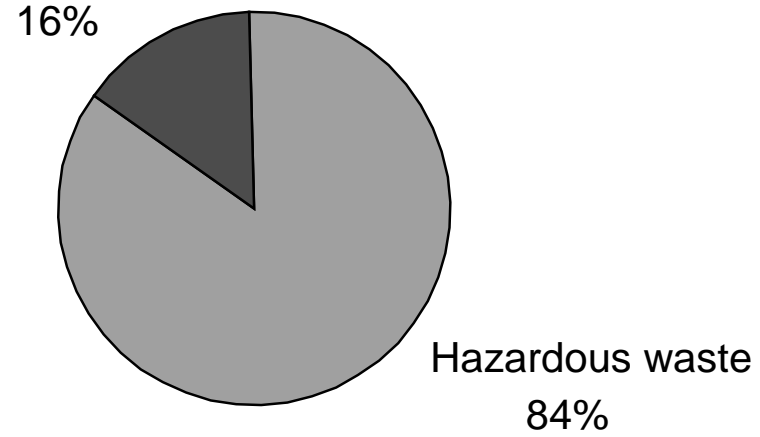

(c)

\section{Linoleum evaluated with ecoscarcity}

Relative contribution of environmental impacts

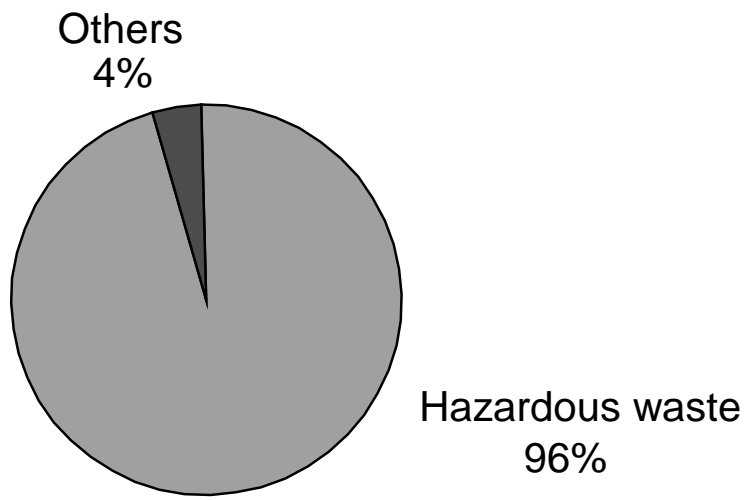

(d) 
Figure 2 Weighting example shown to the participants. The relative contribution of various environmental impacts to the total environmental load of PVC and linoleum flooring, evaluated with two weighting methods: EPS (a-b), Ecoscarcity (c-f). The methods lay emphasis on different impacts. (continued)
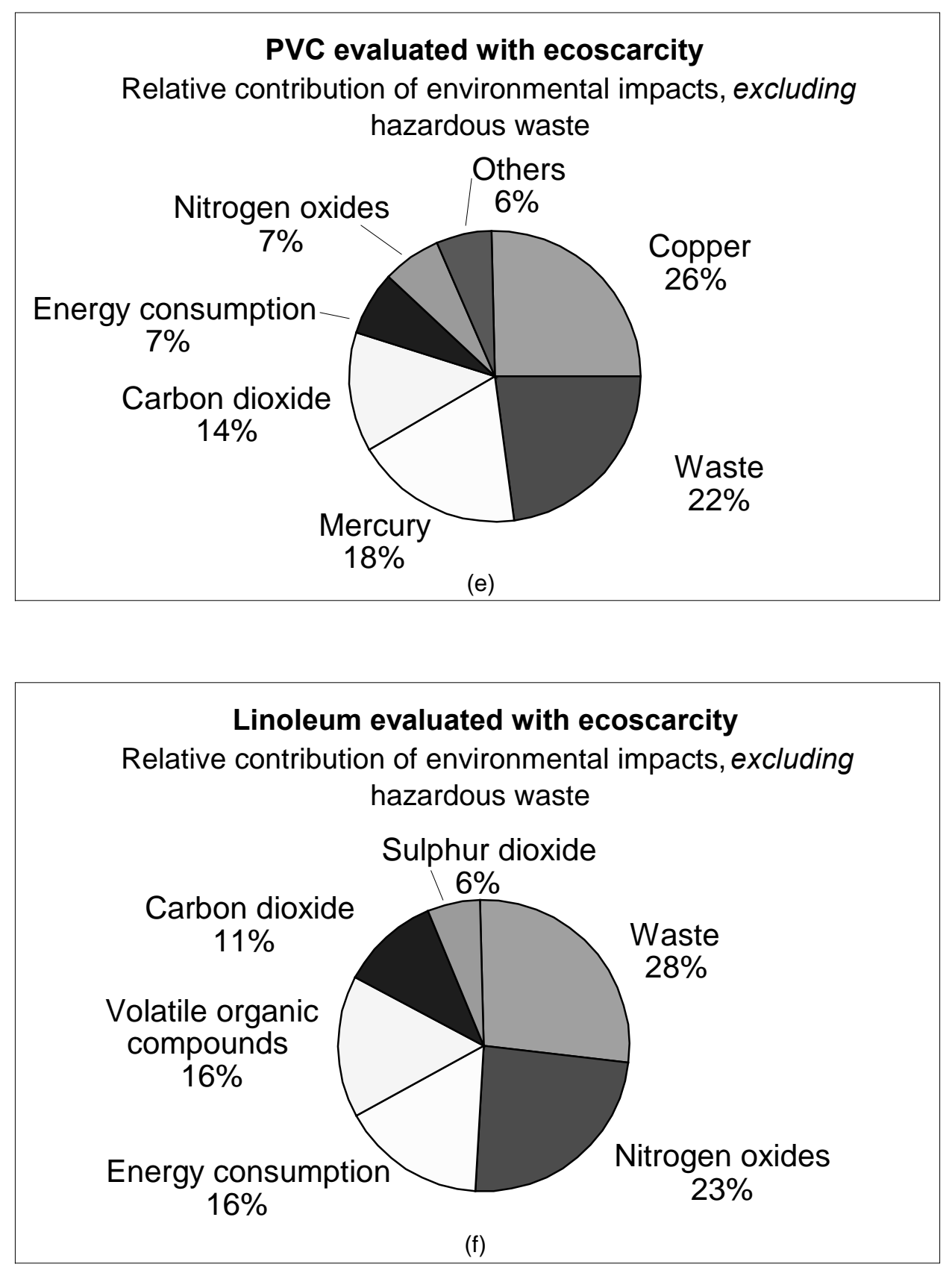
Some participants, especially those with little experience of LCA, were surprised to see that the two methods could give such dissimilar results. A few participants expressed strong doubts concerning aggregation into single score indicators. 'This is Stone Age!', one participant exclaimed when we presented the aggregated results of the two methods. He continued by saying:

\begin{abstract}
"This example shows you can not make a proper [evaluation] system in such a complex context as environmental questions... You can compare the renewability of two different products...and the toxicity of two different products...not both of them together, you can not do that." [IG 3]
\end{abstract}

In general, the other comments on weighting and aggregation fell largely into two categories: the need to compare results with previous experience and knowledge gained from other sources, and the need to use more than one method. The former point can be illustrated by one participant who pointed out that weighting methods can be of help in trying to understand and draw conclusions from a large amount of complex information. However, in the end, analysts and assessment users have to form their own opinions:

"When you are choosing methods, you have to look at how much it agrees with what you yourself know is important." [IG 1]

The participants' expressed need for comparing results with knowledge gained from other sources illustrates that assessment users want to reach robust conclusions, which they can stand for and argue in favour of. Formal weighting methods can strengthen or weaken the conviction that a certain conclusion is correct, but their role might not be decisive.

When talking about the need for using several methods another participant said:

"These methods, they are so shaky that when you use them it is extremely useful to have different methods with different starting points that really illustrate how big the differences can be." [IG 2]

The quotation indicates the value of highlighting differences among methods and principles, and among the results reached by applying those methods. However, one participant who noted that there might be a resistance to complex information, questioned the feasibility of using many methods:

"I have found that decision makers do not want to hear about statistical dispersion, they want a number. That makes it much easier to make a decision." [IG 3]

This participant was worried of those who demand simple answers since it might lead to less robust outcomes.

In summary, we found a considerable scepticism towards methods that aggregate results into single score indicators. The participants emphasised that even though there may be a demand for simple answers to complex questions, it is valuable for analysts and assessment users to evaluate environmental trade-offs from dissimilar perspectives. Consequently, they stressed the need for using several methods which is in line with the recommendations given in most LCA guidelines (for example Lindfors et al., 1995; Guinée, 2001; Udo de Haes et al., 2002). 


\subsubsection{Weighting principles}

After discussing weighting and aggregation in general, we presented four principles that have been used for developing weighting methods in LCA. We were interested in the participants' opinions on these principles and whether they regarded them as useful in assessments for producing convincing results.

\section{Economic measures}

In two of the interviews, with the mixed group and the authorities group, economic measures of environmental impact were criticised on several grounds. Among these criticisms were that the results of economic methods appear to be more objective than they actually are, and that all values seem interchangeable once expressed in the same monetary unit.

Some participants, mainly in the authorities group, were less sceptical to economic measures. However, they also pointed out that such measures need to be handled with care because of their uncertainty. In the purchasers group, some participants thought reliable economic measures would be very useful, but they also realised the difficulties of assigning monetary value to environmental impacts.

\section{National political targets}

The political system was frequently mentioned as an important value source for assessments. Some participants viewed environmental priority-setting mainly as a political issue.

However, problems with the use of political targets were also identified such as differences among countries. Participants in the authorities group pointed out that priorities, in many cases, also differ among geographical levels. In assessments, it is often necessary to handle both local and national environmental concerns, even though these may conflict.

According to some participants, it is not clear to what extent political goals are relevant to decisions in a particular company or organisation. Such goals already influence decisions through various control measures such as environmental taxes and permits; their relevance beyond these measures is not obvious. In summary, political goals seem to be important value sources, but they cannot be used mechanically; their relevance for the specific situation needs to be determined.

\section{Critical load estimates}

The role of natural science in assessments was acknowledged in all groups, but so was the limited capability of science to resolve trade-offs. However, the principle of critical load estimates ${ }^{3}$ received general support, not least from the participating environmental scientists. Even so, some participants expressed their concerns regarding scientists who are often so specialised that few are able to define critical load levels in a consistent way for many different environmental problems. 


\title{
Panels
}

Panel-based methods form a special case since the principle is of a more procedural kind than the others presented. The use of panels for weighting received relatively strong support in the interviews. Most participants could easily understand and relate to panels because they had experience or knew of cases where panels were used, even though these experiences were mostly unrelated to the use of panels in LCA. One participant compared LCA panels to the kind of consumers' panels arranged to investigate market response to new products. Another participant described the use of panels for product assessments in the following way:

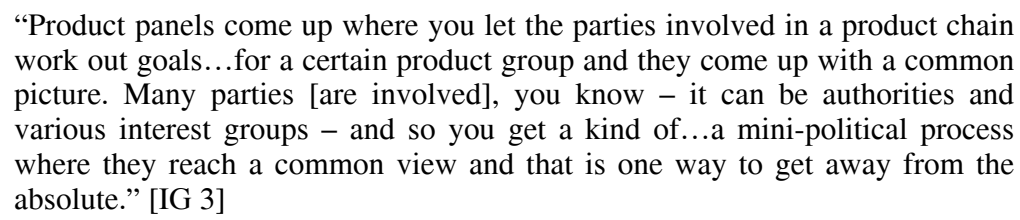

Two different purposes of using panels were identified. First, panels are used to gain a broader understanding of a situation. This relates to the need to learn about other actors' values and to ensure that no important aspects are omitted in the evaluation process:

"It is interesting to hear several different groups approach the same figures,
arrive at different weightings, and then justify why they have done what they
have done. Suddenly you have a new breadth to your thinking." [IG 2]

The second purpose of using panels is to find a consensus. However, one participant felt that there is a danger in using consensus-seeking panels, since important knowledge may be disregarded when compromises are made.

The participants also pointed out that arranging panels is time consuming and costly. This may therefore be only feasible for large organisations and in certain situations:

\begin{abstract}
"One objection to this is that it takes a heck of a lot of time, since you have to discuss just about everything - who should be included and who is responsible for the decisions that are made - and just imagine if there is some disagreement. But on the other hand...with complex problems it may be necessary to let the debate bring out something and it will not be the most optimum result in the world, but that is what you have to do." [IG 3]
\end{abstract}

The composition of panels was mentioned as a crucial point which needs careful handling, but the participants did not express any clear preferences as to how panellists ought to be selected.

\section{The combination of principles}

None of the participants was willing to select one generally preferred principle. They acknowledged that in assessment processes, the knowledge of scientists is vital, political priorities play an important role, and inputs from various interest groups are valuable. Consequently, the combination of principles and the use of panels were preferred by some participants. 


\subsubsection{Impact assessment in general}

Some participants questioned the relevance of current impact assessment methods. One reason was related to the emphasis on quantification. In their view, there is a risk that environmental impacts that are relatively easy to quantify and not dependent on the specific conditions of emission and exposure (for example greenhouse gases) get undue attention. The participants who were concerned over this potential bias argued that problems related to chemicals are often underestimated, just because those problems are more complex and therefore difficult to express in a simple way. A few participants were also concerned about the limited capacity of impact assessment methods to handle synergistic or antagonistic effects between various emissions.

The importance of keeping systems for impact assessment up-to-date with the latest knowledge was stressed by many participants. However, it was also pointed out that there is a need for some stability, so that assessments are not too sensitive to short-lived trends. The need for being open to new findings and stability raises the question of how to decide when there is sufficient agreement for an emerging environmental problem to be included in impact assessments. In the future there will be new, previously unknown, environmental hazards, and it is likely that these will be contested for some time until they are widely accepted.

According to our experience, LCA is more suitable for analysing well-established environmental problems than emerging environmental hazards with large uncertainties pertaining to their causes and effects. Misunderstandings can occur when actors have little knowledge about the strengths and limitations of LCA. Examples of such reactions can be found in the LCA literature. Tukker (1999) showed that LCAs carried out by the Dutch chlorine industry did not match the concerns of the environmental movement. In this case, the environmental movement did not accept the industry's arguments which showed that some chlorinated products had lower life-cycle energy consumption than comparable alternatives. The industry's LCA studies missed the point of the environmental movement's criticism of the industry: that it was irresponsible to introduce chlorinated chemicals into society when the health effects of most of these substances were largely unknown. As a result, the studies did not contribute to resolving the controversy.

\subsection{4 'Dig where you stand' vs. full life-cycle}

Some participants said that in certain situations, a company may have more pressing environmental issues to investigate and improve than life-cycle performance. A company may be regarded as having a higher responsibility for its own direct emissions and its own consumption of resources than for environmental impacts up-stream and down-stream the life cycle. Gradually, the scope of concern and analysis can be expanded and more parts of the life cycle can be taken into account:

\footnotetext{
"It's the old environmental principle of digging where you stand, that is, you start by doing something about what you are responsible for yourself. That way you have a better chance of being an example for others." [IG 2]
}

This would imply that those who carry out environmental assessments and communicate results from such assessments cannot take for granted that the intended audience regards the life-cycle perspective as the most relevant frame of analysis. There might be other 
ways of looking at the situation which are considered correct and legitimate. Hence, in some cases there may be a need for more narrow system boundaries that include only the activities directly related to the company in question.

\subsubsection{Different stages - different concerns?}

Some participants in the current study noted that actors along a product chain tend to focus on different environmental aspects depending on their position in the chain. Solér (2001), and Haugland and Grönhaug (1988 cited Solér, 2001) observed similar phenomena. Producers of consumer goods often focus on health-related factors, such as the content of hazardous substances, while actors further up-stream in the product chain may give more attention to production-related parameters such as emission of pollutants and energy consumption.

Since actors along a product chain operate in different business environments with dissimilar demands, they may have reasons for prioritising different environmental aspects. Hence, a universal perspective which can be applied in the assessment of the product life cycle may not exist. This points at a potential conflict between the holistic perspective of LCA and the need for assessment results to be adapted to suit a specific audience. When actors at different stages of a product chain disagree on environmental priorities and therefore draw dissimilar conclusions from an LCA, it may be hard to reach agreement on what should be done to improve the environmental performance of that chain. This might impede changes that require coordinated action from two or more actors in the product chain.

\subsection{Product assessments and environmental values}

This part deals with environmental assessments of products in a more general sense than strict LCA. Based on the participants' experiences, it seeks to identify factors that may complicate assessments and render difficult the handling of environmental values.

\subsection{1 'The environment' - an ambiguous issue?}

Environmental problems are multidimensional, and the term refers to a broad range of issues, most often without a clear delimitation. Hence, the term 'the environment' is inherently ambiguous, and it often needs clarification. One participant expressed her feelings about working with environmental issues in the following way:

\footnotetext{
"Well, the environment is so much more than just the environment. Sometimes you do not really know what you are talking about I believe. Since the environment is just as much safety as quality, humanism, or morality, the further you go with this concept the more difficult and the more dangerous it becomes." [IG 1]
}

Furthermore, traditional environmental protection, aimed at protecting ecosystems and human health, has become increasingly linked to and integrated with other sustainability concerns such as resource conservation and social issues. From the participants' discussion, it is clear that the broadening of 'the environment' to sustainability has led to increased complexity and ambiguity. Some participants expressed concerns about this broadening, saying there is a risk that traditional environmental issues will be paid less attention. 
A large number of concepts are used to indicate that a product has high environmental performance. When shown a selection of such concepts, the participants thought that while some concepts are relatively well-defined, for example 'recyclable', their environmental relevance is seldom obvious. Other concepts, such as 'environmentally smart', were regarded as more able to cover all relevant concerns, but on the other hand more vague and in need of more clarification. It seems difficult to find concepts that both cover all relevant concerns about products' environmental performance, and, at the same time, are clearly defined. Table 2 gives examples of simple and complex product concepts, and lists benefits and drawbacks.

Table 2 Benefits and drawbacks of two classes of product-related environmental information. Information from complex system models with many built-in assumptions, such as LCA, belongs in the right hand column

\begin{tabular}{ll}
\hline $\begin{array}{l}\text { Simple product information } \\
\text { (Examples: recyclable, made of renewable }\end{array}$ & $\begin{array}{l}\text { Complex product information } \\
\text { (Examples: environmentally adapted, }\end{array}$ \\
materials, the producer has an environmental & environmentally efficient, not harmful to \\
management system, biodegradable) & the environment) \\
\hline+ Easy to communicate & + Easy to communicate on a general level \\
+ Easy to define and verify & + High overall relevance \\
- Overall benefits not obvious & - Difficult to define and verify \\
& - Risk of false consensus \\
\hline
\end{tabular}

The risk of misunderstanding and false consensus caused by the ambiguity was illustrated by one participant who had been working in a project that aimed at improving the environmental performance of lubricants. In that project, it had gradually become clear that environmental improvements meant different things to different project members. Some wanted to focus on toxicity, while others were mostly concerned with finding products made from renewable resources. Even though the project was entirely aimed at environmental improvements, the significance of various aspects of 'the environment' had not been clarified.

\subsubsection{Environmental market communication}

Some participants said that in many situations, they would avoid talking about 'environmentally friendly products', preferring terms such as 'smart products' or 'high-quality products'. A large number of consumers were reported to have negative attitudes towards "environmentally friendly products" due to beliefs that such products lack in functionality and quality.

We also noted that there are trends in how terms and concepts are used. Some participants said that concepts tend to go out of fashion after some time when they are replaced with others. Even though there may be reasons for inventing new terms and concepts, such renewal may further increase the ambiguity of environmental issues.

Because of the ambiguity of 'the environment', companies may experience difficulties when communicating the results of improvement efforts to their customers. This might be one reason why none of the participants said that they viewed environmental adaptation as a strong marketing argument at the time being. For example, some participants discussed the use of LCA in marketing, and noted that LCA results currently seem to have low relevance when used for such purposes: 
"LCA and environmental friendliness, it's like...they are not selling points, since nobody believes this stuff. It is so fuzzy that it disappears." [IG 3]

Participants with experience in the transportation and building industries reported that few companies in these industries seemed to use environmental arguments in marketing.

\subsubsection{Market-driven improvements and the risk of value vacuums}

One of our research objectives was to investigate the participants' views on how and by whom environmental priorities ought to be set. According to some participants, product-related environmental issues are best handled by the marketplace; the environmental priorities expressed by the customer should be the ultimate guiding principles for a company's environmental efforts. According to this logic, environmental performance of products is not essentially different from other product characteristics. For example, if customers emphasise reductions in greenhouse gas emissions, producers should concentrate their efforts on reducing these emissions, and pay less attention to other environmental aspects.

However, the purchasers in our study said that they did not think they had the necessary knowledge to tell the suppliers what environmental aspects should be prioritised:
"It is not certain that I, as the purchaser of a product, am an expert on the problems related to it, since I may be more of an expert on the problems related to my own manufacturing. And so you have to trust that the person who manufactures this product is aware of what is actually most important." [IG 1]

The purchasers said that the demands they place on suppliers should be of a general kind, communicating 'the level of environmental ambition', and that it is the responsibility of the suppliers to prioritise among environmental impacts. Some purchasers reported a trend from detailed technical demands to more general statements and to yes/no demands that are easy to verify:
"At first, we were all over them and said, 'if we do not get this and this and this in these products, and if the detergent needs to contain such and such we won't buy it,' but we do not do that today. Instead, we demand environmental management systems, we offer advice and support, it is more a dialogue all along." [IG 1]

Similarly, a study of the Swedish car and energy industries (Jönsson, 2000) showed that market interest in environmental improvements was often restricted to yes/no demands, such as complying with the requirements for an environmental label, using an Environmental Management System (EMS), or being able to provide customers with Environmental Product Declarations (EPD). The use of such demands can be interpreted as a response to the ambiguity of environmental issues discussed earlier.

Thus, if the purchasers express priorities only in the level of 'having an EMS' or similar, the idea that companies should listen to the market for environmental priorities seems difficult to realise. From this we conclude that there is a risk of what we would like to call value vacuums, situations where producers and their customers expect each other to set priorities. In such cases, the responsibility for pointing out the direction for desired improvements will not be taken by any of the actors. The result might be a lack of focus and slow progress towards more sustainable product systems. 
Value vacuums may also arise in the use of EPDs. Here, producers say that they want to supply their customers with value-free information that can serve as a basis for environmentally conscious purchasing. However, Solér (2001) found that purchasers did not think they could adequately assess EPDs when trade-offs among environmental aspects were involved. Likewise, there seems to be a risk that no one takes responsibility for resolving trade-offs.

\subsubsection{The use of formal methods in assessments}

When the participants talked about environmental assessments of products and comparisons between products, materials, and suppliers, they did not emphasise the role of formal methods. Purchasers said that their product appraisals were mostly based on experience and intuition, and they had difficulties describing in detail how such appraisals are made. It was also pointed out that not all relevant environmental characteristics of products can be expressed quantitatively; other kinds of information play an important role. They said that different kinds of knowledge need to be taken into account and integrated. This supports the results we found when discussing weighting methods in LCA.

The participants gave two concrete examples of product assessments where the integration of different perspectives and different kinds of information was seen as crucial: the criteria-setting for an environmental label, and the selection of items for an exhibition of environmentally friendly products. The former was described as an "interactive process involving the knowledge of a number of different actors" [IG 1]. A seemingly important goal in both examples is to arrive at a robust decision by minimising the risk of neglecting important concerns. This goal was achieved through the inclusion of actor groups that represented a range of experiences and values.

We found that most participants felt at ease with setting environmental priorities on a case-to-case basis. In their view, priorities may differ substantially between one situation and another, but this was not seen as a major problem:

"In every situation, there comes a time when you have to ask yourself, 'Which
environmental aspect is the most important?' I believe there are just as many
answers to this question as there are environmental aspects to a certain
situation, and this means there is also no global standard that can be applied to
a certain product group." [IG 2]

As also noted in Section 3.1.1, some participants stressed the need to form one's own opinion rather than to use ready-made weighting methods that reflect someone else's values:

"I do not think you can get anywhere by accepting...judgements made by someone else... But I believe you have to... reach your own opinion about what is important." [IG 1]

However, individual preferences and values are not formed in isolation from the surrounding society. Preferences are influenced by the issues that concern customers, by others working in the same organisation, by relevant authorities, by media coverage, etc. What actors and sources of information are regarded as important will vary among individuals, usually depending on the situation. 


\subsubsection{The role of experts and science in assessments}

The participants reported that since more and more people gain experience of dealing with information on products' environmental performance, there is an increasing awareness of the complexity of environmental issues. Even so, they noted that many people do not fully understand the need for handling values in environmental assessments. They said that they themselves had only gradually understood and accepted that environmental assessments always involve judgement and therefore, that such assessments cannot produce undisputable answers. This lack of understanding was seen as a problem, in particular by the participants working for public authorities. Problems arise when private companies, politicians, and other actors want the authority to make clear-cut recommendations concerning the environmental performance of products:

"P: Well, they call the authority and ask what we recommend and we pass, of course, since we can't make those decisions.

MB: So then you are sometimes forced into an expert role that you do not really want to be in?

P: We can't, we can't make those decisions." [IG 3]

One of the participants in the authorities group had been involved in the establishment of a database on environmentally sound products. He was frustrated over the difficulties of combining this task with the neutral role that is expected of the agency. Similarly, a purchaser from the public sector reported that she is expected to base buying decisions on 'objective criteria', while she knows that environmental demands cannot be objective in a strict sense:

\footnotetext{
"We are not allowed to just think that something is good or bad, but we have to have an objective criterion and the requirements must be objectively substantiated somehow." [IG 1]
}

Often, this dilemma was solved by formulating demands that are easy to verify, e.g., by demanding that suppliers should have EMSs or that products should be free from some specific material or additive. These are objective demands in the sense that there is little room for disagreement about whether the demand is met or not, but the demands are not objective in the sense that they are free from judgement. Thus, the expectation of objectivity has been met on one level, while nonetheless, there is room for subjective choices. In our opinion, 'objective' may be a misleading word to use in such contexts, since people may wrongly get the impression of something absolute and irrefutable.

In summary, there seem to be high expectations that science and experts will provide clear-cut and objective answers as to what is environmentally preferable. The lack of such answers is a source of frustration both among experts and decision makers. For example, participants working for public authorities generally regarded environmental priority setting as a political task, but pointed out that politicians often have difficulties setting such priorities. We think this is another example of a situation where there is a risk of value vacuums, situations in which two groups expect each other to point out the desired direction for environmental improvements. 


\section{Discussion and conclusion}

To handle environmental trade-offs in product assessments is far more complex than merely to select a ready-made formal weighting method. Environmental assessments are part of social contexts where assessment users and interested parties have their own values and opinions on what is preferable from an environmental point of view. Hence, assessments do not start from scratch, but depend on established ways of thinking. These mind-sets may be challenged, but they are not easily changed. However, existing ways of thinking should not primarily be regarded as obstacles to be overcome by authoritative assessments, but rather as resources for an assessment. They can also be seen as raw materials for producing relevant and convincing results. Assessments that are based on a thorough understanding of interested parties' perspectives and values are more likely to be effective. We believe this is one reason why several participants favoured panel approaches.

In the introduction, three criteria of effective environmental assessments were described: saliency, credibility and legitimacy. The results presented illustrate that environmental product assessments and the decisions based upon them will not necessarily gain acceptance just because credible and scientifically correct information is sent to the target audiences. To be able to handle environmental assessments effectively, companies need to also take into account the saliency and legitimacy dimensions. This requires that they, at least, learn about the priorities and concerns of other actors. Shared interpretations can be reached through dialogues. Two-way communication has the potential to promote learning, thereby laying the groundwork for efficient action. Therefore, companies may gain advantages if they develop their capacity for collaborative learning and dialogues on environmental values across organisational boundaries. Methods that can assist such collaborative learning would be valuable.

The participants in the present study stated that assessments need to be informed by a wide range of perspectives to produce robust results. Thus, methods that can accommodate and integrate various views and perspectives may be more likely to produce effective results. The purpose of such methods would be to facilitate structured discussions on environmental values and priorities, rather than to easily resolve trade-offs. The development of such methods could gain inspiration from recent advances in risk research (for example Multi-Criteria Mapping (Stirling and Mayer, 1999)), in environmental policy analysis (for example Stakeholder Dialogue Analysis (Clark et al., 1998)), and in science and technology assessment (for example Deliberative Mapping (Davies et al., 2003)).

Constraints in time and resources limit the possibility of engaging stakeholders in dialogues, and it is neither feasible nor desirable to do this for every assessment or in every situation that needs decision. In response to the need for simplified assessment methods, increased standardisation has often been called for in the LCA literature (for example Guinée, 2001; Hertwich et al., 2002). However, the participants in the present study emphasised the uniqueness of assessment situations and the need for analysts to take into account different aspects and concerns according to circumstances. Even though standardised approaches may be beneficial in some situations, it cannot be determined beforehand whether such approaches will lead to salient and legitimate outcomes in a specific case. It may turn out that important interested parties have concerns that are not sufficiently met by the standardised methods. By relying too much on standardised 
assessment methods and paying too little attention to the situational characteristics, analysts run the risk of producing ineffective outcomes.

The study indicated a support for panel-based approaches to weighting, but observed several criticisms against economic methods. The support for panels agrees with the recommendations given in the most recent guidelines on LCA (Guinée, 2001; Udo de Haas et al., 2002). However, Udo de Haas et al. (2002) also recommend economic methods. Even though methods based on economic data may seem appealing from a theoretical perspective, they might lack in credibility among users and audiences of environmental assessments. Investigations of how various users and audiences think about economic measures of environmental impacts would be valuable for future development of methods.

Based on the interviews, we observed a risk for value vacuums, situations where it is not clear who should set environmental priorities. The clearest example of value vacuum was found in the relationship between companies and their customers. On the one hand, we found the idea that companies should listen to their customers for guidance on environmental priorities. On the other hand, we noticed that industrial purchasers did not think they had the required competence, or that it was their responsibility, to place explicit environmental demands on the suppliers. Value vacuums were shown to be potential problems since in such cases, environmental improvements may be overshadowed by other concerns. Value vacuums can be caused by actors' lack of understanding of the epistemological basis of environmental product assessments. As found in this study, it can be a difficult and lengthy process for a person to understand that such assessments need to involve both descriptive and normative elements, and to realise what implications this has for assessments. Value vacuums can also be the result of actors' unwillingness to engage in discussions on normative issues related to environmental priorities. Such unwillingness might be due to a lack of time and resources, a lack of experience and competence, or an unwillingness to make normative choices that may be contested.

One way to avoid value vacuums and the associated risks of confusion and slow environmental progress is for actors in product chains to initiate dialogues with each other on the normative bases of environmental assessments and decision making. In addition, for increased transparency, companies can try to formulate environmental policies and guidelines that more clearly indicate their priorities than what is commonly seen today. A task for future research would be to further investigate why value vacuums arise, what consequences they have and how they may be handled.

Another observation was that it seems difficult to find concepts to describe environmentally adapted products. These concepts are usually either too specific or too general. In the former case they fail to cover the whole range of issues related with sustainability and environmental adaptation. In the latter, they are usually defined too vaguely to give any real commitment and direction for improvements. These difficulties are somehow linked with problems caused by value vacuums. If actors do not realise the need for defining sustainability and environmental improvements, and the need for handling values and trade-offs, there is a risk of false consensus where actors believe they agree, but actually have dissimilar ideas.

The participants also reported a tendency to express demands for environmental adaptation only in yes/no terms. We interpreted this as a result of the perceived vagueness of environmental and sustainability issues, and the difficulties to clearly define 
what an improvement in these areas means. The consequence of this tendency is also a kind of value vacuum since yes/no demands usually give little or no guidance on how to deal with trade-offs.

When discussing panels for environmental evaluation, the participants identified two separate purposes of using such approaches: to promote learning and to find consensus. This distinction can be linked to the more general question of the function of environmental product assessments. One way of looking at assessments emphasises their instrumental function, their ability to provide specific decision situations with relevant information, and to bring any disagreement to a closure by providing an authoritative statement (assessments as decision tools). This function is in line with the rational model of decision making which is common in classical decision theory. Another way of looking at assessments emphasises their role in promoting learning among diverse actors, in bringing people together, and in catalysing change processes (assessments as processes of social learning). This perspective is closer to descriptive decision theory, which emphasises the ambiguous character of decision processes where information is usually incomplete, preferences vaguely articulated, and serendipities often play an important role (e.g., March, 1994). Processes of social learning contains elements such as building up shared problem perceptions, building trust as a base for critical self-reflection, recognising mutual dependencies among actors, reflecting on subjective values, and engaging in joint problem solving (Pahl-Wostl, 2002). Most research on environmental product assessments has been based on the rational model of decision making, while few efforts have been made to improve understanding of the other function of assessments: how they can support social learning. This virtually blind spot opens challenging opportunities for further interdisciplinary research on environmental product assessments.

\section{Acknowledgment}

The study was carried out as part of CPM, the Swedish national competence centre in environmental assessment of product and material systems. CPM is jointly funded by the Swedish Agency for Innovation Systems, Chalmers University of Technology, and a group of industrial companies. We wish to express our gratitude to the participants who took the time to share their experiences and opinions with us. We are also indebted to the anonymous reviewers who gave valuable comments on earlier versions of this article.

\section{References}

Barbour, R.S. and Kitzinger, J. (Eds.) (1999) Developing Focus Group Research: Politics, Theory and Practice, London: Sage.

Baumann, H. and Rydberg, T. (1994) 'Life cycle assessment: a comparison of three methods for impact analysis and evaluation', Journal of Cleaner Production, Vol. 2, No. 1, pp.13-20.

Baumann, H., Ekvall, T., Eriksson, E., Kullman, M., Rydberg, T., Ryding, S-O., Steen, B. and Svensson, G. (1993) 'Miljömässiga skillnader mellan återvinning/återanvändning och förbränning/deponering [Environmental differences between recycling/reuse and incineration/landfilling]', Reforsk FoU Report 71, in Swedish, Malmö: Stiftelsen Reforsk.

Bengtsson, M. (1998) 'Värderingsmetoder i LCA [Valuation methods in LCA]', CPM-Rapport, in Swedish, Göteborg: Chalmers tekniska högskola, Vol. 1. 
Bengtsson, M. (2001) 'Weighting in practice: implications for the use of life-cycle assessment in decision making', Journal of Industrial Ecology, Vol. 4, No. 4, pp.47-60.

Bloor, M., Frankland, J., Thomas, M. and Robson, K. (2001) Focus Groups in Social Research, London: Sage.

Bras-Klapwijk, R.M. (1999) 'Adjusting life cycle assessment methodology for use in public policy discourse', Ph.D. Thesis, Delft: Delft University of Technology.

Braunschweig, A., Förster, R., Hofstetter, P. and Müller-Wenk, R. (1996) Developments in LCA Valuation, IWÖ-HSG Diskussionsbeitrag, St. Gallen: Universität St. Gallen, No. 32.

Clark, J., Burgess, J., Dando, N., Bhattachary, D., Heppel, K., Jones, P., Murlis, J. and Wood, P. (1998) 'Prioritising the issues in local environment agency plans through consensus building with stakeholder groups', Technical Report W114, Bristol: UK Environment Agency.

Clark, W. and Dickson, N. (1999) 'The global environmental assessment project: learning from efforts to link science and policy in an interdependent world', Acclimations, Vol. 8, pp.6-7.

Davies, G., Burgess, J., Eames, M., Mayer, S., Staley, K., Stirling, A. and Williamson, S. (2003) 'Deliberative mapping: appraising options for addressing 'The kidney gap', Final Report, online, Available from http://www.deliberative-mapping.org (Accessed 17 February 2005).

European Environmental Agency (EEA) (2001) 'Designing effective assessments: the role of participation, science and governance, and focus', Environmental Issue Report, Copenhagen, No. 26.

van Eeten, M. (1999) Dialogues of the Deaf: Defining New Agendas for Environmental Deadlocks, Delft: Eburon.

Finnveden, G. (1997) 'Valuation methods within LCA: where are the values?', International Journal of LCA, Vol. 2, No. 3, pp.163-169.

Finnveden, G. (1999) 'A critical review of operational valuation/weighting methods for life cycle assessment', AFR-Report 253, Stockholm: AFN, Naturvårdsverket.

Finnveden, G., Hofstetter, P., Bare, J., Basson, L., Ciroth, A., Mettier, T., Seppälä, J., Johansson, J., Norris, G. and Volkwein, S. (2002) 'Normalization, grouping and weighting in life cycle impact assessment', in H. Udo de Haes, G. Finnveden, M. Goedkoop, M. Hauschild, E. Hertwich, P. Hofstetter, O. Jolliet, W. Klöpffer, W. Krewitt, E. Lindeijer, R. Mueller-Wenk, S. Olsen, D. Pennington, J. Potting and B. Steen (Eds.) Life-Cycle Impact Assessment: Striving Towards Best Practice, Pensacola: SETAC.

Guinée, J. (Ed.) (2001) Life Cycle Assessment: An Operational Guide to the ISO Standards, Part 3, Scientific Background, Dutch Ministry of Housing, Spatial Planning and the Environment (VROM), and Centre of Environmental Science, Leiden University.

Hanssen, O.J. (1999) 'Status of Life Cycle Assessment (LCA) activities in the Nordic region', International Journal of LCA, Vol. 4, No. 6, pp.315-320.

Haugland, S.A. and Grönhaug, K. (1988) 'Quality perceptions in international distribution channels', The Finnish Journal of Business Economics, Vol. 37, No. 2, pp.107-115.

Hertwich, E., Pease, W. and Koshland, C. (1997) 'Evaluating the environmental impact of products and production processes: a comparison of six methods', The Science of the Total Environment, Vol. 196, pp.13-29.

Hertwich, E., Pennington, D. and Bare, J. (2002) 'Introduction', in H. Udo de Haes, G. Finnveden, M. Goedkoop, M. Hauschild, E. Hertwich, P. Hofstetter, O. Jolliet, W. Klöpffer, W. Krewitt, E. Lindeijer, R. Mueller-Wenk, S. Olsen, D. Pennington, J. Potting and B. Steen (Eds.) Life-Cycle Impact Assessment: Striving Towards Best Practice, Pensacola: SETAC.

Jönsson, A. (1995) 'Life cycle assessment of flooring materials: a case study and methodological considerations', Thesis (Licentiate). Technical Environmental Planning Report, Göteborg: Chalmers University of Technology, No. 3.

Jönsson, K. (2000) 'Communicating the environmental characteristics of products', Thesis (Licentiate), The International Institute for Industrial Environmental Economics, Lund: Lund University. 
Lindeijer, E. (1996) 'Normalisation and valuation', in H. Udo de Haes (Ed.) Towards a Methodology for Life Cycle Impact Assessment, Brussels: Society of Environmental Toxicology and Chemistry-Europe.

Lindfors, L-G., Christiansen, K., Hoffman, L., Virtanen, Y., Juntilla, V., Hanssen, O.J., Rønning, A., Ekvall, T. and Finnveden, G. (1995) 'Nordic guidelines on life-cycle assessment', Nord, Copenhagen: Nordic Council of Ministers, No. 20.

March, J.G. (1994) A Primer on Decision Making: How Decisions Happen, New York: The Free Press.

Pahl-Wostl, C. (2002) 'Towards sustainability in the water sector: the importance of human actors and processes of social learning', Aquatic Sciences, Vol. 64, pp.394-411.

Pennington, D.W., Potting, J., Finnveden, G., Lindeijer, E., Jolliet, O., Rydberg, T. and Rebitzer, G. (2004) 'Life cycle assessment part 2: current impact assessment practice', Environment International, Vol. 30, pp.721-739.

Powell, J.C., Pearce, D.W. and Craighill, A.L. (1997) 'Approaches to valuation in LCA impact assessment', International Journal of LCA, Vol. 2, No. 1, pp.11-15.

Solér, C. (2001) 'Communication of product related environmental information: user requirement studies of Environmental Product Declaration, EPD, systems', CPM Report, Göteborg: Chalmers University of Technology, No. 4.

Steen, B. and Ryding, S-O. (1992) 'The EPS enviro-accounting method: an application of environmental accounting principles for evaluation and valuation of environmental impact in product design', IVL Report B 1080, Göteborg: Swedish Environmental Research Institute (IVL).

Stirling, A. and Mayer, S. (1999) Rethinking Risk, SPRU, University of Sussex.

Tukker, A. (1999) Frames in the Toxicity Controversy: Risk Assessment and Policy Analysis Related to the Dutch Chlorine Debate and the Swedish PVC Debate, Dordrecht: Kluwer Academic Publishers.

Udo de Haes, H., Finnveden, G., Goedkoop, M., Hauschild, M., Hertwich, E., Hofstetter, P., Jolliet, O., Klöpffer, W., Krewitt, W., Lindeijer, E., Mueller-Wenk, R., Olsen, S., Pennington, D., Potting, J. and Steen, B. (Eds.) (2002) Life-Cycle Impact Assessment: Striving Towards Best Practice, Pensacola: SETAC.

\section{Notes}

1 Life-cycle based environmental product declarations aim to be objective. EPDs express environmental information in terms of a product's contribution to a number of impact categories, such as acidification and global warming, but do not include any weighting of these categories. In ISO terminology, EPDs are called Type III environmental declarations.

2 These methods were used in Jönsson (1995), and even though they may be regarded as obsolete by now, we chose to use them to illustrate how weighting methods can be used in assessments.

3 A principle according to which environmental impacts are compared based on the ratio between the present environmental load and the estimated level of long-term sustainability. Environmental problems with higher ratios are regarded as more severe and given higher priority. 